\title{
Impact of chitosan-based nanocarriers on cytoskeleton dynamics: Current status and challenges
}

\author{
M. Carolina Di SANTO ${ }^{1,2, *}$; Agustina AlaimO ${ }^{1,2, *}$; Ana Paula Domínguez RUBIO ${ }^{1,2}$; Oscar E. PÉReZ ${ }^{1,2, *}$ \\ 1 Departamento de Química Biológica, Facultad de Ciencias Exactas y Naturales, Universidad de Buenos Aires, Buenos Aires, Argentina \\ 2 Instituto de Química Biológica de la Facultad de Ciencias Exactas y Naturales, Consejo Nacional de Investigaciones Científicas y Técnicas (IQUIBICEN- \\ CONICET), Buenos Aires, Argentina
}

Key words: Cytoskeletal dynamics, Cellular uptake, Endocytosis, Nanocarriers, Chitosan, Bioactive compounds

\begin{abstract}
Chitosan-based nanocarriers (CS-NCs) show a promising role in improving drugs and bioactive compounds delivery for therapy. However, the effects exerted by CS-NCs at the cellular level, including their recognition and uptake, have not been fully investigated yet. Many factors, including size, shape, concentration, and surface chemistry of CS-NCs, play an important role in determining the types of intracellular signals triggered. The mechanism of uptake and the involvement of the cytoskeleton during the CS-NCs endocytosis variates among the different cell types as well as further effects observed inside cells. In the present work, we discuss the effects induced by CS-NCs per se on the cytoskeleton, a key component in cell architecture and physiology. The focus of this report is made on tumoral and normal biological models in which CS-NCs could differentially affect the cell cytoskeleton. The recent years reports regarding the impact of CS-NCs on cytoskeleton dynamics and the current techniques for its evaluation are summarized and discussed. Understanding mechanisms underlying cytoskeletal impact after cell exposure to CS-NCs is critical for the design of safest value-added formulations in the biomedical field. Furthermore, this revision points out some interesting aspects of cytoskeletal changes and cell death encompassing anti-tumoral effects.
\end{abstract}

$\begin{array}{ll}\text { Abbreviations } \\ \text { BCs: } & \text { bioactive compounds } \\ \text { CM-CS: } & \text { carboxymethyl chitosan } \\ \text { CMI: } & \text { carboxymethyl inulin } \\ \text { CS: } & \text { chitosan } \\ \text { CS-NCs: } & \text { chitosan-based nanocarriers } \\ \text { DS: } & \text { dextrane sulphate } \\ \text { HAP: } & \text { hydroxyapatite } \\ \text { mV: } & \text { milliVolts } \\ \text { NCs: } & \text { nanocarriers } \\ \text { nm: } & \text { nanometer } \\ \text { PCL: } & \text { polycaprolactone } \\ \text { PLGA: } & \text { poly (lactic-co-glycolic acid) } \\ \text { PO-500: } & \text { hexaglycerin penta ester } \\ \text { PVL: } & \text { Poly (Vinyl Alcohol) } \\ \text { TPP: } & \text { pentasodium tripolyphosphate }\end{array}$

*Address correspondence to: Oscar E. Pérez, oscarperez@qb.fcen.uba.ar

${ }^{\#}$ Both authors contributed equally to this work

Received: 21 July 2021; Accepted: 06 October 2021

\section{Introduction}

Bioactive compounds (BCs) are substances that have biological activity, related to its capability to modulate one or more metabolic processes (Angiolillo et al., 2015). BCs are present as natural constituents in food, providing health benefits beyond the basic nutritional value of the product (DeFelice, 1992). These compounds can be applied for pharmaceutical or nutraceutical purposes (Sansone et al., 2019). Nutraceuticals, a term invented in 1989 by Stephan DeFelice, reflect their existence in the human diet and their biological activity.

Nanomedicine is a rapidly expanding area among life sciences which is mostly dominated by the production of nanocarriers (NCs) for drugs and BCs protection (Ahmad et al., 2021). The nanodelivery system has several advantages, such as overcoming the limitations and problems that comprise conventional pharmaceutical agents, older formulations, and delivery systems (Bayda et al., 2020; Buosi et al., 2020). The assessment of NCs biocompatibility is closely related to cytotoxicity and adverse effects they can potentially induce on target cells. Also, the control of the internalization mechanisms has become a challenge in the design process of the physicochemical characteristics of the NCs to be used (Rennick et al., 2021). Into this framework, the 
cellular uptake of NCs has been investigated in terms of the cellular and/or tissue environment, the dynamics of the cytoskeleton, and the capacity to activate specific cellular pathways during the internalization process (Donahue et al., 2019; Sousa de Almeida et al., 2021; Vtyurina et al., 2021).

In the present point of view, the focus was put on the impact of CS-NCs on cytoskeletal dynamics when experimenting in different biological systems (normal and tumoral cells). We summarized and discussed recent years reports addressing this topic, by adding information about type of CS-NCs employed, biological models used and main outcomes. The current techniques used for cytoskeleton analysis after CS-NCs exposure and vacancy areas for research were reviewed.

\section{Nanocarriers Uptake, Trafficking Routes, and Cytoskeletal Organization}

Increasing research in NCs used for biomedical applications raises a concern about how they can interact with cells beyond their therapeutic purposes. In this line, there are four points with crucial implications for their biological impact. Firstly, NCs cellular uptake and intracellular trafficking routes depend on the intrinsic physicochemical properties, like size, surface functionalization, charge, stiffness, and topography shape as well as the colloidal stability ( $\zeta$-potential). Secondly, the route of administration (e.g., intraocular, intravenous, intramuscular inhalation, topical, oral). Thirdly, the cell/tissue target, and the specific cell uptake route employed to internalize NCs in the process of endocytosis (Sousa de Almeida et al., 2021). Particularly, the primary cellular mechanisms of uptake are (a) clathrin-dependent (b) caveolin-dependent (c) clathrin- and caveolin-independent (d) macropinocytosis and (e) phagocytosis (Donahue et al., 2019; Rennick et al., 2021). The NCs uptake rate depends on the triggered endocytosis mechanism. Notably, the same type of NCs could be internalized by different endocytosis mechanisms according with the cellular type, physiological state, variations in the cell membrane curvature, presence, or absence of specific receptor sites as well as surfactant molecules that prevent serum proteins from binding to the surface of NCs efficiently (Rennick et al., 2021; Sousa de Almeida et al., 2021). Fourthly, the involvement of the cytoskeleton during the endocytosis, which is a highly dynamic network of microfilaments, intermediate filaments, and microtubules. This 3D network ensures cell shape maintenance, strength, and structural integrity as well as a rail for active transport mechanisms (Shahzad et al., 2020; Mastrogiovanni et al., 2020). Moreover, the cytoskeleton allows the transmission of mechanical signals, being a key structure within the internal environment for cell survival, differentiation, migration, and proliferation (Finkenstaedt-Quinn et al., 2016). Cell types constituting the different tissues do not use the same intracellular trafficking routes for the same kind of NCs. In other words, the involvement of the cytoskeleton dynamics fluctuates among the different cell types (Gilleron et al., 2013).

\section{Chitosan-Based NCs Uptake and Its Impact on the Cytoskeleton Dynamics}

Chitosan (CS) is a linear polysaccharide whose structure is comprised of $\beta$-1,4-linked 2-amino-2-deoxy- $\beta$-D-glucose (deacetylated D-glucosamine) and $\mathrm{N}$-acetyl-D-glucosamine units (di Santo et al., 2020b). The substantial attention of CS in the pharmaceutical and biomedical fields resides in its biodegradable, biocompatible and non-toxic features (PrudkinSilva et al., 2020). Also, CS's amine groups are responsible for its cationic nature, controlled drug release, muco-adhesion, permeation enhancement, etc. As a result, CS is one of the most employed polysaccharides in the drug delivery design strategies for administration of BCs (di Santo et al., 2020a; Dubashynskaya et al., 2020; Prudkin-Silva et al., 2020).

The interactions between CS-NCs and cellular membranes produce a reversible structural rearrangement of the binding proteins, encompassing a specific rearrangement of the cytoskeletal F-actin and tight-binding proteins. Such ability allows CS and CS-NCs to enhance mucosal absorption of drugs through all routes of administration, contributing to an increased bioavailability (Zhao et al., 2018). We found interesting to note that CS observations could be extended to other polymers with similar characteristics, such as PEI (polyethylenimine) and PLL (poly-l-lysine), whose molecules can also enter cells via endocytosis and affect the cytoskeleton functionality. In fact, CS, PEI and PLL are widely used in transfection tests due to their low cytotoxicity and cationic nature (Wang et al., 2019). Particularly, due to latter characteristics, the mechanism of PEI-mediated gene delivery has been well demonstrated in many literature studies. As a polycation, PEI will spontaneously adhere to and condense exogenous DNA to form spherical complexes that cells readily uptake. These complexes can interact with the cell membrane and, consequently, be endocytosed. Once into the cell, vesicle movement depends on the cytoskeleton (Grosse et al., 2007), and PEI/DNA complexes also travel along the cytoskeletal network up to the nucleus (Zhang et al., 2011). Thus, the functioning of the cytoskeleton is affected by this transport showing a parallelism with CS-NCs effects.

The information collected and offered in this report summarizes the employment of CS-NCs for pharmaceutical and biomedical ends in both in vitro and in vivo models, for which cytoskeletal effects have been reported. The lack of consensus on the cytoskeletal alterations that is described in Table 1 could be related with the wide variability in methodological approaches for NCs design. Furthermore, the concentration of proteins in culture medium determines whether the NCs would be adsorbed, and these interactions regulate the promotion or inhibition of their internalization. Depending on the type of endocytosis, specific internalization pathways ensure differential trafficking of NCs inside cells (Yameen et al., 2014). The scheme shown in Fig. 1 refers to a generalized case without specifying a particular route of endocytosis. After their release into the cytoplasm, NCs give rise to a signal cascade that culminates in the triggering of a major cellular event. The latter differs whether the cellular context is a physiological or a tumor environment. Those cascades may or may not be accompanied by the cytoskeleton network reorganization depending on the physicochemical characteristics of the CS-NCs delivered to the target cell type. Additionally, dose, concentration and/or exposure time of the NCs are critical variables for both, the internalization, 


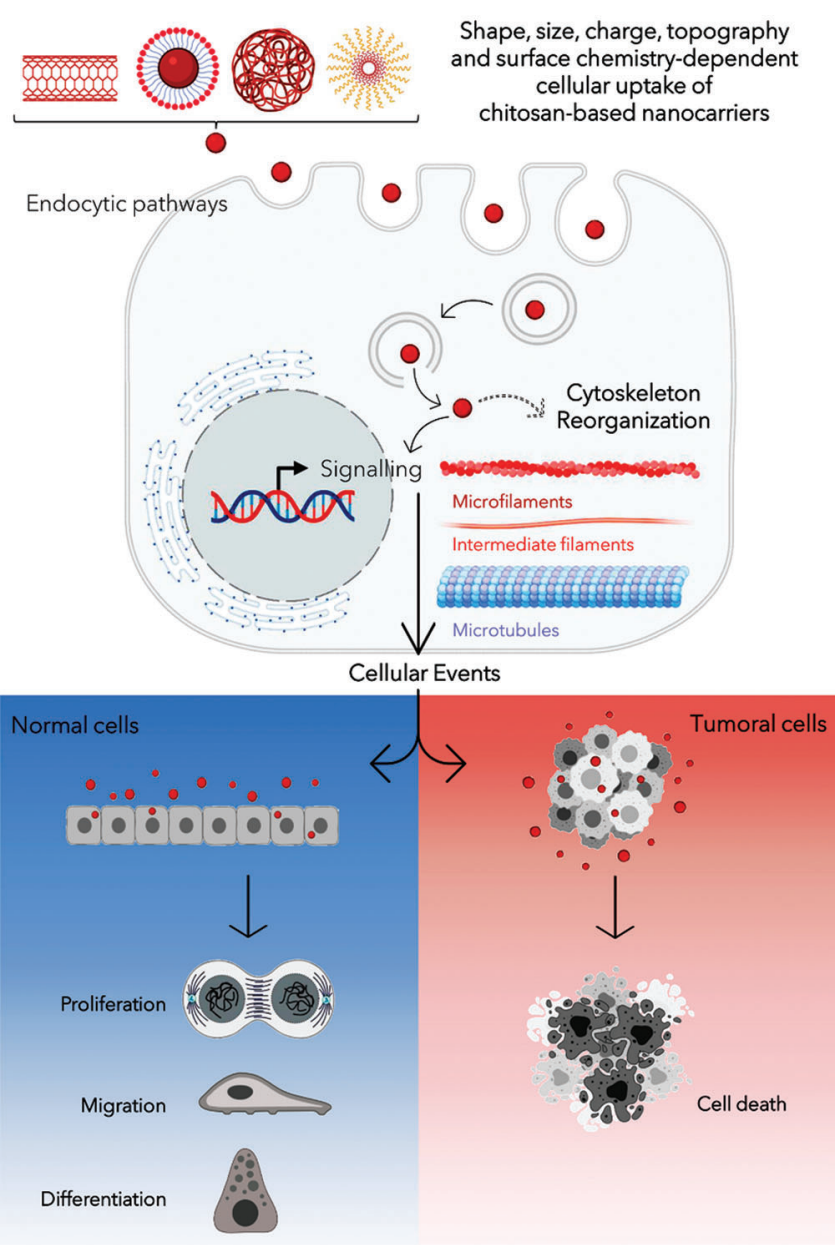

FIGURE 1. Schematic diagram summarizing the interaction among chitosan-based nanocarriers (CS-NCs) and mammalian cells. Created with BioRender platform.

and biological effects. After the cellular uptake of CS-NCs, transient effects could be observed in the cytoskeletal organization, along with the propagation of intracellular signals (Fig. 1). When CS-NCs do not affect cell viability, as mostly occurs in normal cells, they can occasionally trigger biological responses, e.g., cell migration. The latter could be the case observed in macrophages (Coya et al., 2019) and lymphocytes (Lin et al., 2019). Those cells, due to their activity in immunity, exhibit asymmetrical changes in their morphology (polarization) and mobility (chemotaxis), whose events are regulated by microtubules and microfilaments (Billadeau et al., 2007; Gomez and Billadeau, 2008). Notably, it has been reported that CS-NCs can stimulate T-cell maturation and proliferation (Malik et al., 2018). Also, the macrophage nitric oxide (NO) production and chemotaxis were assigned to the $\mathrm{N}$-acetylglucosamine unit present in the CS structure rather than to the glucosamine residue. Furthermore, the CS-induced immune stimulatory response resulted to be highly specific since other glycosaminoglycans, such as $\mathrm{N}$-acetyl-o-mannosamine and N-acetyl-p-galactosamine, had no effects on NO production. Similar stimulatory effects were detected on lymphocytes (Peluso et al., 1994).

The "Cell Death Nomenclature Committee" (Kroemer et al., 2008) formulates guidelines for the definition and interpretation of morphological, biochemical, and functional perspectives observed in different cell death. The most robust guide was reported by Galluzzi et al. (2018) and one-year later, an update was published by Tang et al. (2019). Nowadays, cell death is categorized into two types: accidental cell death and programmed cell death. At the same time, the latter is subclassified in apoptosis, necroptosis, lysosome-dependent cell death, autophagy-dependent cell death, ferroptosis, pyroptosis, netosis, parthanatos, entosis, anoikis, mitotic death, oxeiptosis, autosis, alkaliptosis. Whatever the type of cell death, these guidelines describe the rearrangements that cytoskeletal dynamics could undergo (Kroemer et al., 2008; Galluzzi et al., 2018; Ren et al., 2021). Although the absence of cytotoxicity is a general feature of CS-NCs, in some specific systems, such as tumoral cells, death pathways are triggered (Venkatesan et al., 2011; Taranejoo et al., 2016; Zamproni et al., 2020) (Fig. 1). Thus, the information presented in Table 1 opens some questions: Could CS-NCs differentially affect the tumoral cell cytoskeleton by specific molecular signaling pathways? or is merely a consequence of the chosen experimental conditions, i.e., dose, exposure time, materials combined with CS? The answers to those questions could be found in the report of Abedian et al. (2019), in which, low and high molecular weights (MW) CS resulted biocompatible with normal foreskin-derived fibroblasts. However, both types of CS exhibited growth inhibitory effects against tumoral cell lines, such as HeLa, MCF-7 and Saos-2. As a result of the difference in the mechanism of cytotoxicity between fibroblasts and cancer cell lines, authors hypothesized that the latter have greater cell membrane negative charges than normal cells, which may be more attractive to the positively charged amino groups on CS molecules. In this way, CS could affect tumoral cells directly through interaction with the plasma membrane or extracellularly through a specific receptor, or through endocytosis. Whatever the form, the polysaccharide could alter the cell membrane through electrostatic interaction, leading to the secretion of inflammatory cytokines, such as IL-6 and IL-8 (Abedian et al., 2019). In agreement, Ivanova and Yaneva (2020) highlight two aspects in relation to the anticancer and the immunostimulatory properties of CS:

a) The redox regulatory mechanisms of CS could explain its anticancer activity. That is to say, the initiation of intracellular ROS rise in cancer cells could be closely associated to the activation of intracellular calcium signaling that lead to enhancement of the human defense system and consequently, the apoptotic cell death.

b) The activated human immune system has great potential to destroy cancer cells without being toxic to the healthy tissue and organs. Taken together, the use of CS-NCs could be a cancer treatment option with fewer side effects. However, it is necessary to deeply understand the molecular mechanism that explains the differential response, including in addition in vivo experiments (Abedian et al., 2019).

Visualization techniques are another key issue in the aim to understand the cytoskeletal dynamics. Depending on whether samples are fixed or living cells different information can be acquired from the assay (McKayed and Simpson, 2013; Finkenstaedt-Quinn et al., 2016). There are specific microscopic techniques which require high resolution fluorescent imaging methods that maintain a 
TABLE 1

Impact of CS-NCs on cytoskeleton dynamics

\begin{tabular}{|c|c|c|c|c|}
\hline $\begin{array}{l}\text { Type of } \\
\text { CS-NC }\end{array}$ & $\begin{array}{l}\text { Physicochemical } \\
\text { properties of CS- } \\
\text { NC } \\
\text { mean size } \\
\zeta \text {-potential } \\
\end{array}$ & $\begin{array}{l}\text { Biological model } \\
\text { In vitro (normal or tumoral } \\
\text { cell lines) } \\
\text { In vivo (animals) }\end{array}$ & Major outcomes & References \\
\hline $\mathrm{CS}+\mathrm{TPP}$ & $\begin{array}{l}289 \mathrm{~nm} \\
+35.9 \mathrm{mV}\end{array}$ & $\begin{array}{l}I O B A-N H C \\
\text { Normal. Human } \\
\text { conjunctival cells }\end{array}$ & $\begin{array}{l}\text { No changes were detected in the actin filaments } \\
\text { distribution. }\end{array}$ & $\begin{array}{l}\text { Enríquez de } \\
\text { Salamanca et al. } \\
\text { (2006) }\end{array}$ \\
\hline $\mathrm{CS}+\mathrm{HAP}$ & $\begin{array}{l}144 \mathrm{~nm} \\
-1.8 \mathrm{mV}\end{array}$ & $\begin{array}{l}\text { HCT-15 } \\
\text { Tumoral. Human colon } \\
\text { adenocarcinoma cells }\end{array}$ & $\begin{array}{l}\text { The elongated shape actin filaments network } \\
\text { exhibited alterations. }\end{array}$ & $\begin{array}{l}\text { Venkatesan et al. } \\
\text { (2011) }\end{array}$ \\
\hline $\begin{array}{l}\mathrm{CM}-\mathrm{CS}+ \\
\mathrm{PO}-500\end{array}$ & $\begin{array}{l}219 \mathrm{~nm} \\
+39 \mathrm{mV}\end{array}$ & $\begin{array}{l}\text { HKC } \\
\text { Normal. Human proximal } \\
\text { tubular epithelial cells }\end{array}$ & $\begin{array}{l}\text { No changes were detected in actin filaments } \\
\text { distribution. }\end{array}$ & Yue et al. (2011) \\
\hline $\begin{array}{l}\text { Nanotubes: } \\
\mathrm{CS}+ \\
\text { collagen }\end{array}$ & $\begin{array}{l}40-60 \mathrm{~nm} \\
\text { N.A. }\end{array}$ & $\begin{array}{l}\text { L929 } \\
\text { Normal. Mouse fibroblast } \\
\text { cells }\end{array}$ & $\begin{array}{l}\text { Cytoskeleton did not display the typical fibroblastic } \\
\text { morphology. Cells were mostly rounded. }\end{array}$ & Zhao et al. (2014) \\
\hline $\begin{array}{l}\mathrm{CS}+ \\
\text { lecithin }\end{array}$ & $\begin{array}{l}150-200 \mathrm{~nm} \\
\text { N.A. }\end{array}$ & $\begin{array}{l}M D C K-C 7 \\
\text { Normal. Canine kidney } \\
\text { epithelial cells }\end{array}$ & $\begin{array}{l}\text { Cell migration that correlated with moderate } \\
\text { cytoskeleton alterations. Actin filaments } \\
\text { redistribution and reduction. }\end{array}$ & Kaiser et al. (2015) \\
\hline $\mathrm{CS}+\mathrm{CMI}$ & $\begin{array}{l}70 \mathrm{~nm} \\
+20 \mathrm{mV}(\mathrm{pH}< \\
7.6)\end{array}$ & $\begin{array}{l}M D A-M B-231 \\
\text { Tumoral. Human breast } \\
\text { adenocarcinoma cells } \\
\text { NIH3T3 } \\
\text { Normal. Mouse fibroblasts }\end{array}$ & $\begin{array}{l}\text { The cytomorphology and the tubulin cytoskeleton } \\
\text { were not altered. }\end{array}$ & Merli et al. (2016) \\
\hline $\mathrm{CS}+\mathrm{TPP}$ & $\begin{array}{l}93 \mathrm{~nm} \\
+14 \mathrm{mV}(\mathrm{pH} \mathrm{7.4}) \\
+55 \mathrm{mV}(\mathrm{pH} \mathrm{3})\end{array}$ & $\begin{array}{l}\text { SW48 } \\
\text { Tumoral. Human colon } \\
\text { adenocarcinoma cells }\end{array}$ & Changes in microfilament contents (F-actin). & $\begin{array}{l}\text { Taranejoo et al. } \\
(2016)\end{array}$ \\
\hline $\mathrm{CS}+\mathrm{TPP}$ & N.A. & $\begin{array}{l}\text { MCF } 10 \mathrm{~A} \\
\text { Normal. Human mammary } \\
\text { epithelial cells }\end{array}$ & No negative influence on the cytoskeleton. & Catalano (2017) \\
\hline $\begin{array}{l}\text { CS }+ \text { Oleic } \\
\text { Acid }+ \\
\text { Span } 85+ \\
\text { Tween } 20\end{array}$ & $\begin{array}{l}104 \mathrm{~nm} \\
+21 \mathrm{mV}\end{array}$ & $\begin{array}{l}\text { Human macrophages } \\
\text { differentiated from CD14+ } \\
\text { monocyte }\end{array}$ & $\begin{array}{l}\text { CS-NC were internalized via an actin cytoskeleton- } \\
\text { dependent process. }\end{array}$ & $\begin{array}{l}\text { De Matteis et al. } \\
\text { (2016); Coya et al. } \\
(2019)\end{array}$ \\
\hline $\mathrm{CS}+\mathrm{TPP}$ & $\begin{array}{l}50 \mathrm{~nm} \\
+28 \mathrm{mV} \text { (water). } \\
-4 \mathrm{mV} \text { (culture } \\
\text { media with serum) }\end{array}$ & $\begin{array}{l}H G F \\
\text { Normal. Human gingival } \\
\text { fibroblasts }\end{array}$ & No visible changes in cytoskeleton arrangement. & Martin et al. (2019) \\
\hline $\mathrm{CS}+\mathrm{TPP}$ & $\begin{array}{l}113 \mathrm{~nm} \\
+54 \mathrm{mV}\end{array}$ & $\begin{array}{l}\text { Human } \mathrm{V} \gamma 9 \mathrm{~V} \delta 2 \mathrm{~T}- \\
\text { lymphocytes }\end{array}$ & $\begin{array}{l}\text { No changes in the } \alpha \text {-tubulin and } \beta \text {-actin expression } \\
\text { levels. } \\
\alpha \text {-tubulin cytoskeleton rearrangement was detected. }\end{array}$ & Lin et al. (2019) \\
\hline CS-DS & $\begin{array}{l}186 \mathrm{~nm} \\
-25 \mathrm{mV}\end{array}$ & $\begin{array}{l}\mathrm{N} 2 a \\
\text { Tumoral. Murine } \\
\text { neuroblastoma cells }\end{array}$ & $\begin{array}{l}\text { Neurotoxicity correlates with changes in } \beta \text {-tubulin } \\
\text { distribution. }\end{array}$ & $\begin{array}{l}\text { Zamproni et al. } \\
(2020)\end{array}$ \\
\hline $\begin{array}{l}\mathrm{CS}+ \\
\mathrm{PLGA}\end{array}$ & $\begin{array}{l}254 \mathrm{~nm} \\
+22 \mathrm{mV}\end{array}$ & $\begin{array}{l}\text { HUVEC } \\
\text { Normal. human umbilical } \\
\text { vein endothelial cells }\end{array}$ & $\begin{array}{l}\text { No changes were detected in the actin filaments } \\
\text { organization and expression levels. }\end{array}$ & Jin et al. (2021) \\
\hline $\begin{array}{l}\text { 3-layer } \\
\text { nanofiber: } \\
\text { CS+ PCL/ } \\
\text { PVL/ } \\
\mathrm{CS}+\mathrm{PCL}\end{array}$ & $\begin{array}{l}103 \mathrm{~nm} \\
\text { N.A. }\end{array}$ & Skin of male Wistar rats & $\begin{array}{l}\text { The NF has no effect on alpha-smooth muscle actin } \\
\text { mRNA expression. }\end{array}$ & $\begin{array}{l}\text { Mirmajidi et al. } \\
\text { (2021) }\end{array}$ \\
\hline
\end{tabular}

Note: N.A. = not available data. 
perfect focus and optimal cellular growth conditions. Confocal laser scanning microscopy (CLSM) is the most widely used technique since $z$-section imaging of samples can be performed. However, many reports showed images acquired with epifluorescence equipment, which has less resolution. On the other hand, atomic force microscopy (AFM) allows the simultaneous measurement of local cell elasticity and living or fixed cell topography with high spatial resolution and force sensitivity (Finkenstaedt-Quinn et al., 2016). The combination of AFM and CLSM has become a common strategy to investigate the correlation between cytoskeletal rearrangement and mechanical response or morphology changes, especially in living cells, as shown by Lin et al. (2019). Moreover, Correlative Light and Electron Microscopy (CLEM) has become a highly fashionable method (Svitkina, 2019). It bridges the spectrum of dyes and probes which in turn enable the localization of molecules of interest within living cells by fluorescence microscopy with the cellular ultrastructure from electron microscopy (de Boer et al., 2015). The different CLEM methods have played an active role in developing strategies to capture and study dynamic events at high-resolution in in vitro and in vivo models (Jin et al., 2021). Despite the improved spatial resolution of CLSM, cytoskeletal structures smaller than the "Abbe diffraction limit" cannot be detected. In this sense, super resolution fluorescence imaging like stochastic optical reconstruction microscopy (STORM), photoactivated localization microscopy (PALM), and stimulated emission depletion fluorescence microscopy (STED), could resolved those limitations (FinkenstaedtQuinn et al., 2016).

\section{Conclusions and Future Perspectives}

NCs delivery systems have the potential to improve the treatment of various diseases. The cellular uptake and trafficking of NCs are critical processes to understand how they reach the site of action. In this context, there are few reports related to the internalization process of CS-NC and its cellular impact; hence, the aim of this contribution was to recapitulate their effect on the cytoskeleton dynamics.

Greater understanding of the uptake process can potentially be obtained to take advantage of cellular biological mechanisms for more efficient delivery of CSNCs. Studies comparing cytoskeletal distribution, cell functions, and cytotoxicity with the same type of CS-NCs assessed in a variety of cell lines is needed to clarify these issues. Is it really possible to modulate endocytosis to favor therapeutic administration through the use of CS-NCs by any particular route? would be the arising question. Thus, the use of specific pharmacological inhibitors or key receptor gene silencing of each endocytic pathway could be explored. In this sense, these tools could add further knowledge to the understanding of the interactions between CS-NC and target cells. Either way, despite it being somewhat complex to draw general conclusions, it is evident that CS-NCs can be a useful vehicle for drug and BCs delivery. Likewise, the lack of studies on this topic reveals a vacant area that must be rigorously explored for the successful implementation of NCs in biomedical applications.
Acknowledgement: M.C.DS thanks postdoctoral fellowship from ANPCyT, Argentina.

Authors' Contribution: The authors confirm contribution to the paper as follows: M.C.DS, A. and A.P. DR wrote the first draft. O.E.P critically reviewed the draft. All authors reviewed and approved the final version of the manuscript.

Funding Statement: ANPCyT (PICTs 2015-3866 and 20171683), Universidad de Buenos Aires UBACyT 20020190100297BA and CONICET.

Conflicts of Interest: The authors declare that they have no conflicts of interest to report regarding the present study.

\section{References}

Abedian Z, Moghadamnia AA, Zabihi E, Pourbagher R, Reza Nouri $\mathrm{H}$ et al. (2019). Anticancer properties of chitosan against osteosarcoma, breast cancer and cervical cancer cell lines. Caspian Journal of Internal Medicine 10: 439.

Ahmad R, Srivastava S, Ghosh S, Khare SK (2021). Phytochemical delivery through nanocarriers: A review. Colloids and Surfaces B: Biointerfaces 197: 111389. DOI 10.1016/j. colsurfb.2020.111389.

Angiolillo L, Del Nobile MA, Conte A (2015). The extraction of bioactive compounds from food residues using microwaves. Current Opinion in Food Science 5: 93-98. DOI 10.1016/j. cofs.2015.10.001.

Bayda S, Adeel M, Tuccinardi T, Cordani M, Rizzolio F (2020). The history of nanoscience and nanotechnology: From chemicalphysical applications to nanomedicine. Molecules 25: 112 . DOI 10.3390/molecules25010112.

Billadeau DD, Nolz JC, Gomez TS (2007). Regulation of T-cell activation by the cytoskeleton. Nature Reviews Immunology 7: 131-143. DOI 10.1038/nri2021.

Buosi FS, Alaimo A, Di Santo MC, Elías F, García Liñares G et al. (2020). Resveratrol encapsulation in high molecular weight chitosan-based nanogels for applications in ocular treatments: Impact on human ARPE-19 culture cells. International Journal of Biological Macromolecules 165: 804-821. DOI 10.1016/j.ijbiomac.2020.09.234.

Catalano E (2017). In vitro biological validation and cytocompatibility evaluation of hydrogel iron-oxide nanoparticles. AIP Conference Proceedings 1873: 1-8. DOI 10.1063/1.4997140.

Coya JM, de Matteis L, Giraud-Gatineau A, Biton A, Serrano-Sevilla I et al. (2019). Tri-mannose grafting of chitosan nanocarriers remodels the macrophage response to bacterial infection. Journal of Nanobiotechnology 17: 1-15. DOI 10.1186/ s12951-018-0439-x.

de Boer P, Hoogenboom JP, Giepmans BNG (2015). Correlated light and electron microscopy: Ultrastructure lights up! Nature Methods 12: 503-513. DOI 10.1038/nmeth.3400.

de Matteis L, Alleva M, Serrano-Sevilla I, García-Embid S, Stepien G et al. (2016). Controlling properties and cytotoxicity of chitosan nanocapsules by chemical grafting. Marine Drugs 14: 175 . DOI $10.3390 / \mathrm{md} 14100175$.

DeFelice SL (1992). The nutraceutical initiative: A recommendation for U.S. economic and regulatory reforms. Genetic Engineering News 12: 4-15.

di Santo MC, Alaimo A, Acebedo SL, Spagnuolo CC, Pozner RG, Pérez OE (2020a). Biological responses induced by high molecular weight chitosan administrated jointly with 
platelet-derived growth factors in different mammalian cell lines. International Journal of Biological Macromolecules 158: 953-967. DOI 10.1016/j.ijbiomac.2020.05.032.

di Santo MC, Alaimo A, Dominguez Rubio A, de Matteo R, Pérez OE (2020b). Biocompatibility analysis of high molecular weight chitosan obtained from Pleoticus muelleri shrimps. Evaluation in prokaryotic and eukaryotic cells. Biochemistry and Biophysics Reports 24: 100842. DOI 10.1016/j. bbrep.2020.100842.

Donahue ND, Acar H, Wilhelm S (2019). Concepts of nanoparticle cellular uptake, intracellular trafficking, and kinetics in nanomedicine. Advanced Drug Delivery Reviews 143: 6896. DOI 10.1016/j.addr.2019.04.008.

Dubashynskaya N, Poshina D, Raik S, Urtti A, Skorik YA (2020). Polysaccharides in ocular drug delivery. Pharmaceutics 12: 1-30.

Enríquez de Salamanca A, Diebold Y, Calonge M, García-Vazquez C, Callejo $S$ et al. (2006). Chitosan nanoparticles as a potential drug delivery system for the ocular surface: Toxicity, uptake mechanism and in vivo tolerance. Investigative Ophthalmology \&Visual Science 47: 1416-1425.

Finkenstaedt-Quinn SA, Qiu TA, Shin K, Haynes CL (2016). Superresolution imaging for monitoring cytoskeleton dynamics. Analyst 141: 5674-5688.

Galluzzi L, Vitale I, Aaronson SA, Abrams JM, Adam D et al. (2018). Molecular mechanisms of cell death: Recommendations of the Nomenclature Committee on Cell Death 2018. Cell Death \& Differentiation 25: 486-541.

Gilleron J, Querbes W, Zeigerer A, Borodovsky A, Marsico G et al. (2013). Image-based analysis of lipid nanoparticle-mediated siRNA delivery, intracellular trafficking and endosomal escape. Nature Biotechnology 31: 638-646.

Gomez TS, Billadeau DD (2008). T cell activation and the cytoskeleton: You can't have one without the other. Advances in Immunology 97: 1-64.

Grosse S, Aron Y, Thévenot G, Monsigny M, Fajac I (2007). Cytoskeletal involvement in the cellular trafficking of plasmid/PEI derivative complexes. Journal of Controlled Release 122: 111-117. DOI 10.1016/j.jconrel.2007.06.015.

Ivanova D, Yaneva Z (2020). Antioxidant properties and redoxmodulating activity of chitosan and its derivatives: Biomaterials with application in cancer therapy. BioResearch Open Access 9: 64-72. DOI 10.1089/biores.2019.0028.

Jin H, Zhao Z, Lan Q, Zhou H, Mai Z et al. (2021). Nasal delivery of hesperidin/chitosan nanoparticles suppresses cytokine storm syndrome in a mouse model of acute lung injury. Frontiers in Pharmacology 11: 1-10.

Kaiser M, Pereira S, Pohl L, Ketelhut S, Kemper B et al. (2015). Chitosan encapsulation modulates the effect of capsaicin on the tight junctions of MDCK cells. Scientific Reports 5: 114. DOI 10.1038/srep10048.

Kroemer G, Galluzi L, Vandenabeele P, Abrams J, Alnemri ES et al. (2008). Classification of cell death: Recommendations of the Nomenclature Committee on Cell Death 2009. Cell Death Differ 16: 3-11.

Lin L, He J, Li J, Wu Y (2019). Chitosan nanoparticles strengthen $\mathrm{V} \gamma 9 \mathrm{~V} \delta 2 \mathrm{~T}$-cell cytotoxicity through upregulation of killing molecules and cytoskeleton polarization. International Journal of Nanomedicine 14: 9325-9336. DOI 10.2147/IJN.

Malik A, Gupta M, Mani R, Gogoi H, Bharnagar R (2018). Trimethyl chitosan nanoparticles encapsulated protective antigen protects the mice against anthrax. Frontiers in Immunology 9: 1-12. DOI 10.3389/fimmu.2018.00562.
Martin V, Ribeiro IAC, Alves MM, Gonçalves L, Almeida AJ et al. (2019). Understanding intracellular trafficking and antiinflammatory effects of minocycline chitosan-nanoparticles in human gingival fibroblasts for periodontal disease treatment. International Journal of Pharmaceutics 572: 118821. DOI 10.1016/j.ijpharm.2019.118821.

Mastrogiovanni M, Juzans M, Alcover A, di Bartolo V (2020). Coordinating cytoskeleton and molecular traffic in $\mathrm{T}$ cell migration, activation, and effector functions. Frontiers in Cell and Developmental Biology 8: 1138. DOI 10.3389/fcell.2020.591348.

McKayed KK, Simpson JC (2013). Actin in action: Imaging approaches to study cytoskeleton structure and function. Cells 2: 715-731. DOI 10.3390/cells2040715.

Merli D, Pivi F, Profumo A, Quadrelli P, Milanese C et al. (2016). Carboxymethylinulin-chitosan nanoparticles for the delivery of antineoplastic mitoxantrone. ChemMedChem 11: 2436-2444. DOI 10.1002/cmdc.201600385.

Mirmajidi T, Chogan F, Rezayan AH, Sharifi AM (2021). In vitro and in vivo evaluation of a nanofiber wound dressing loaded with melatonin. International Journal of Pharmaceutics 596: 120213. DOI 10.1016/j.jpharm.2021.120213.

Peluso G, Petillo O, Ranieri M, Santin M, Ambrosio L et al. (1994). Chitosan-mediated stimulation of macrophage function. Biomaterials 15: 1215-1220. DOI 10.1016/0142-9612(94) 90272-0.

Prudkin-Silva C, Martínez JH, Mazzobre F, Quiroz-Reyes C, SanJuan E et al. (2020). High molecular weight chitosan-based particles for insulin encapsulation obtained via nanospray technology. Drying Technology 2: 1-16. DOI 10.1080/ 07373937.2020.1806863.

Ren W, Zhao W, Cao L, Huang J (2021). Involvement of the Actin Machinery in Programmed Cell Death. Frontiers in Cell and Developmental Biology 8: 634849.

Rennick JJ, Johnston APR, Parton RG (2021). Key principles and methods for studying the endocytosis of biological and nanoparticle therapeutics. Nature Nanotechnology 16: 266276. DOI 10.1038/s41565-021-00858-8.

Sansone F, Mencherini T, Picerno P, Lauro MR, Cerrato M, Aquino RP (2019). Development of health products from natural sources. Current Medicinal Chemistry 26: 4606-4630. DOI $10.2174 / 0929867325666180926152139$.

Shahzad KA, Qin Z, Li Y, Xia D (2020). The roles of focal adhesion and cytoskeleton systems in fluid shear stress-induced endothelial cell response. BIOCELL 44: 137-145. DOI 10.32604/biocell.2020.08500.

Sousa De Almeida M, Susnik E, Drasler B, Taladriz-Blanco P, PetriFink A, Rothen-Rutishauser B (2021). Understanding nanoparticle endocytosis to improve targeting strategies in nanomedicine. Chemical Society Reviews 50: 5397-5434. DOI 10.1039/D0CS01127D.

Svitkina T (2019). Imaging cytoskeleton components by electron microscopy. Methods in Molecular Biology 586: 187-206. DOI 10.1007/978-1-60761-376-3.

Tang D, Kang R, Vanden Berghe T, Vandenabeele P, Kroemer G (2019). The molecular machinery of regulated cell death. Cell Research 29: 347-364. DOI 10.1038/s41422-019-0164-5.

Taranejoo S, Janmaleki M, Pachenari M, Seyedpour SM, Chandrasekaran $\mathrm{R}$ et al. (2016). Dual effect of F-actin targeted carrier combined with antimitotic drug on aggressive colorectal cancer cytoskeleton: Allying dissimilar cell cytoskeleton disrupting mechanisms. International Journal of Pharmaceutics 513: 464472. DOI 10.1016/j.ijpharm.2016.09.056. 
Venkatesan P, Puvvada N, Dash R, Prashanth K, Sarkar D et al. (2011). The potential of celecoxib-loaded hydroxyapatite-chitosan nanocomposite for the treatment of colon cancer. Biomaterials 32: 3794-3806. DOI 10.1016/j.biomaterials.2011.01.027.

Vtyurina N, Aberg C, Salvati A (2021). Imaging of nanoparticle uptake and kinetics of intracellular trafficking in individual cells. Nanoscale 13: 10436-10446. DOI 10.1039/D1NR00901J.

Wang J, Ye X, Ni H, Zhang J, Ju S, Ding W (2019). Transfection efficiency evaluation and endocytosis exploration of different polymer condensed agents. DNA and Cell Biology 38: 1048-1055. DOI 10.1089/dna.2018.4464.

Yameen B, Choi WI, Vilos C, Swami A, Shi J, Farokhzad OC (2014). Insight into nanoparticle cellular uptake and intracellular targeting. Journal of Controlled Release 28: 485-499. DOI 10.1016/j.jconrel.2014.06.038.

Yue ZG, Wei W, Lv PP, Yue H, Wang LY et al. (2011). Surface charge affects cellular uptake and intracellular trafficking of chitosan-based nanoparticles. Biomacromolecules 12: 2440 2446. DOI 10.1021/bm101482r.

Zamproni LN, Teixeira D, Alliegro AA, Longo Maugéri I, des Rieux A, Porcionatto M (2020). Decreased viability and neurite length in neural cells treated with chitosan-dextran sulfate nanocomplexes. Neurotoxicology 76: 33-43. DOI 10.1016/j. neuro.2019.10.001.

Zhang XZ, Zeng X, Sun YX, Zhuo RX (2011). Bioactive materials in gene therapy. Bioactive Materials in Medicine 7: 179-219. DOI 10.1533/9780857092939.2.179.

Zhao D, Yu S, Sun B, Gao S, Guo S, Zhao K (2018). Biomedical applications of chitosan and its derivative nanoparticles. Polymers (Basel) 10: 462. DOI 10.3390/polym10040462.

Zhao W, Yu W, Zheng J, Wang Y, Zhang Z, Zhang D (2014). Effects of carbon nanotubes in a chitosan/collagen-based composite on mouse fibroblast cell proliferation. Cellular and Molecular Neurobiology 34: 43-50. DOI 10.1007/s10571-013-9985-9. 